\title{
The effects of Ginsenosides on PI3K/AKT signaling pathway
}

\author{
Soudeh Ghafouri-Fard ${ }^{1} \cdot$ Neda Balaei $^{2} \cdot$ Hamed Shoorei $^{3} \cdot$ Syed Muhammad Farid Hasan ${ }^{4}$. \\ Bashdar Mahmud Hussen ${ }^{5}$. Seyedeh Fahimeh Talebi ${ }^{6} \cdot$ Mohammad Taheri $^{7}$. Seyed Abdulmajid Ayatollahi ${ }^{8}$
}

Received: 22 November 2021 / Accepted: 15 February 2022 / Published online: 27 February 2022

(c) The Author(s) 2022

\begin{abstract}
Ginsenosides belong to a group of steroid glycosides that are extracted from the plant genus Panax (ginseng). This plant has been used for a long time for the treatment of a variety of disorders in traditional medicine. Recent studies have assessed the biological impact of Ginsenosides in cell culture or animal models. Animal studies have shown their beneficial impacts in the remedy of pathological conditions in different tissues. The ameliorating effects of Ginsenosides in diverse pathogenic conditions can be attributed to their effects on the production of reactive oxygen species. These substances mainly affect the activity of AMPK/AKT and PI3K/AKT pathways. The beneficial effects of Ginsenosides have been appraised in diabetesrelated complications, spinal cord injury, cerebral ischemia, myocardial ischemia, and other disorders which are associated with oxidative stress. Moreover, these substances have been shown to interfere with the pathologic conditions during carcinogenesis. In the current study, we explain these impacts in two distinct sections including non-neoplastic conditions and neoplastic conditions.
\end{abstract}

Keywords Ginsenoside · Gene expression · Signaling pathway

\section{Introduction}

Ginsenosides are a group of steroid glycosides and triterpene saponins being extracted from the plant genus Panax (ginseng). This plant has been used in traditional medicine for a long time. Ginsenosides have a great diversity of delicate and complex biological impacts when assessed separately [1]. Ginsenosides have been extracted from several parts of the plant, although usually from its roots. The purification process can be accomplished using column chromatography [2]. Asian, American, and Japanese species have distinctive chemical features. Asian ginseng (Panax ginseng) is the most extensively studied species because of its use in the traditional Chinese medicine. The majority of known ginsenosides belong to the dammarane family, based on the presence of a 4-ring, steroid-like configuration. A minimum of 2 or 3 hydroxyl groups are attached at the carbon- 3 and -20 positions of the ginsenosides or their carbon- $3,-6$, and -20 positions, respectively. In protopanaxadiols and protopanaxatriols, sugar groups are bound to the carbon- 3 and carbon-6 positions, respectively. $\mathrm{Rb} 1, \mathrm{Rb} 2, \mathrm{Rg} 3, \mathrm{Rh} 2$, and $\mathrm{Rh} 3$ are the most studied protopanaxadiols, while $\mathrm{Rg} 1, \mathrm{Rg} 2$, and Rh1 are famous protopanaxatriols (Fig. 1) [3].

7 Institute of Human Genetics, Jena University Hospital, Jena, Germany

8 Phytochemistry Research Center, Shahid Beheshti University of Medical Sciences, Tehran, Iran 


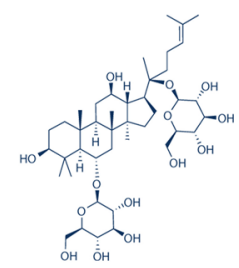

Rg1

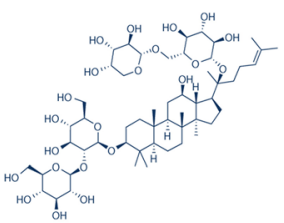

Rb2

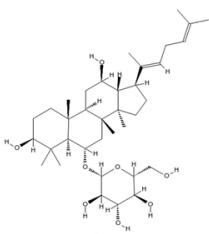

RH4

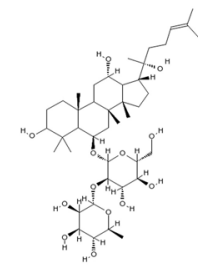

20R-Rg2

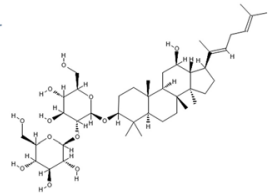

Rg5

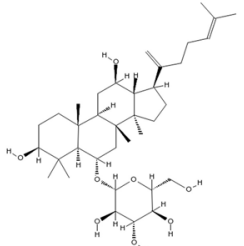

RK3

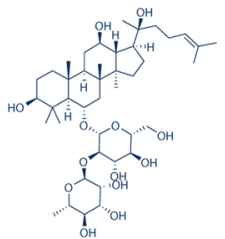

20S-Rg2

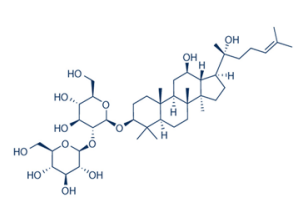

20R-Rg3

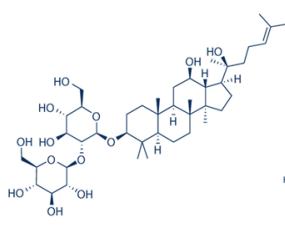

20S-Rg3

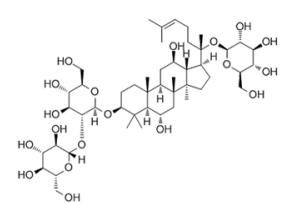

R4

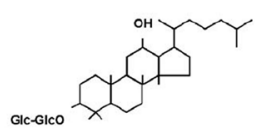

RP1

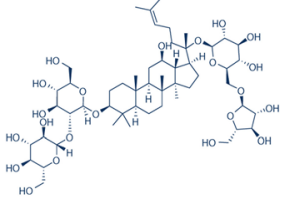

Rc

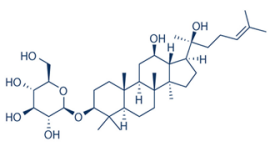

20R-Rh2

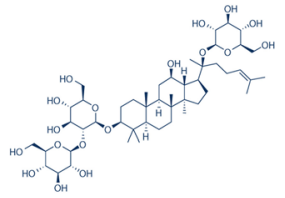

Rd

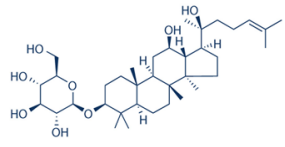

20S-Rh2

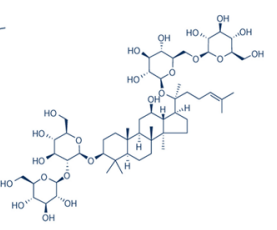

Rb1

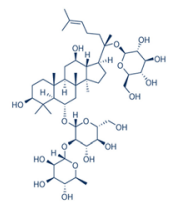

Re

Some Effects of Ginsenosides:

Anti-inflammatory Anti-cancer Anti-oxidant Organ-protective Anti-diabetic Anti-aging

Fig. 1 Chemical structure of some ginsenosides studied in this paper. Ginsenosides are the major constituents found in the plant ginseng. It has been reported that they have unique biological activities such as anti-aging, anti-oxidant, anti-tumor, anti-diabetic, and organ-protective impacts

The biological impact of ginsenosides has been assessed in cell culture or animal models. Animal studies have shown their beneficial impacts in the remedy of pathological conditions in different tissues. In the current study, we explain these impacts in two distinct sections including non-neoplastic conditions and neoplastic conditions.

\section{Non-neoplastic conditions}

\section{Diabetic complications}

The impact of Ginsenoside Rb1 in the amelioration of oxidative stress has been assessed in a bone marrow cell line obtained from a patient with neuroblastoma (SH-SY5Y) following treatment with a highly reactive metabolite of hyperglycemia, namely methylglyoxal (MGO). Ginsenoside $\mathrm{Rb} 1$ has been shown to alleviate the effects of MGO on the activity of superoxide dismutase and catalase and the level of total glutathione. This substance has decreased malondialdehyde levels, amended mitochondrial injury, and reduced production of reactive oxygen species (ROS) (Fig. 2). Besides, this substance has enhanced the Bcl-2/ Bax ratio, decreased levels of cleaved caspase- 3 and cleaved caspase-9, and increased phosphorylated AKT levels. Notably, the ameliorative impact of Ginsenoside Rb1 against
MGO-associated apoptosis has been partially obliterated by an inhibitor of PI3K phosphorylation, implying that Ginsenoside Rb1 amends MGO-associated oxidative stress and apoptosis through enhancing the activity of PI3K/AKT cascade [4].

Ginsenoside Re has been shown to amend high glucose (HG)-induced injury in the retinal endothelial cells through modulation of the effects of PI3K/AKT cascade on HIF- $1 \alpha /$ VEGF signaling. Cell line studies have shown that pre-treatment of these cells with Ginsenoside Re has protected these cells from HG-induced injury, decreased their apoptosis, and reduced ROS production. Ginsenoside Re has also enhanced the expression of HIF- $1 \alpha$ in the cytoplasm but reduced its nuclear levels, implying that this substance decreases nuclear translocation of HIF- $1 \alpha$ and decreases VEGF level. These effects are exerted through enhancing the activity of the PI3K/AKT pathway since they have been abrogated by a specific PI3K inhibitor. Thus, Ginsenoside Re affects the activities of PI3K/AKT and HIF-1 $\alpha$ /VEGF pathways. These effects might be associated with the amelioration of HGassociated retinal angiogenesis [5].

Ginsenoside $\mathrm{Rg} 1$ has been shown to interfere with the effects of tau hyperphosphorylation on diabetic synaptic neurodegeneration of retinal ganglion cells, an early event in the pathogenesis of diabetic retinopathy. The neuroprotective impact of Ginsenoside $\mathrm{Rg} 1$ on diabetic retinae has 
been abolished after the suppression of expression of IRS-1 or AKT. On the other hand, suppression of retinal GSK3 $\beta$ has rescued the neuroprotective effects of Ginsenoside Rg1 when AKT was inhibited. Thus, Ginsenoside Rg1 can stop hyperphosphorylated tau-associated synaptic neurodegeneration of retinal ganglion cells through enhancing the activity of IRS-1/AKT/GSK3 $\beta$ cascade [6]. Table 1 lists the beneficial effects of Ginsenosides in diabetic complications.

\section{Central nervous system}

In vitro studies have shown that Ginsenoside $\mathrm{Rg} 1$ induces remedy of the scratch wound via enhancing the production of laminin and fibronectin as well as several growth factors including NGF, GDNF, and bFGF. In addition, Ginsenoside Rg1 could activate the PI3K/AKT signaling and promote the functional remedy of hindlimb movements in animal models. This substance could also reduce the void area and decrease levels of glial fibrillary acidic protein (GFAP) and chondroitin sulfate proteoglycans. In brief, Ginsenoside $\mathrm{Rg} 1$ can both enhance the scratch wound remedy in cell cultures via induction of expression of neurotrophic factors for astroglial cells and improve the functional remedy in animal models of spinal cord injury (SCI) [17].

Ginsenoside $\operatorname{Rg} 1$ has been found to promote the migratory potential of olfactory ensheathing cells in vitro, and their remedial impact in the treatment of SCI. This substance has enhanced the expression of MMP-2, MMP-9, and NCAM1 genes in olfactory ensheathing cells. Ginsenoside $\operatorname{Rg} 1$ has enhanced the migration of olfactory ensheathing cells through the PI3K/AKT pathway. Pre-treatment of olfactory ensheathing cells Ginsenoside Rg1 has improved their therapeutic efficacy in a rat model of SCI [18].

Ginsenoside Rd via the PI3K/AKT/GSK-3 $\beta$ axis could decrease phosphorylation of tau protein after cerebral ischemia [19]. This substance could also improve neurogenesis after cerebral ischemia through the PI3K/AKT pathway [20]. Table 2 shows the effects of Ginsenosides in disorders of the central nervous system (CNS).

\section{Cardiovascular disorders}

Experiments in rat heart myoblasts have shown that hypoxia induces a reduction in cell viability and increases apoptosis and autophagy in these cells. Notably, Ginsenoside $\operatorname{Rg} 1$ has ameliorated hypoxia-associated changes in these cells without any impacts on their viability under normal oxygen concentrations. Ginsenoside $\mathrm{Rg} 1$ has enhanced phosphorylated levels of important kinases in the PI3K/AKT/mTOR pathway and levels of HIF-1 $\alpha$. Additional in vivo assays have confirmed the effects of Ginsenoside $\operatorname{Rg} 1$ in amelioration of ischemia/ reperfusion injury in rats via enhancing the activity of the PI3K/AKT/mTOR pathway. Therefore, Ginsenoside Rg1 protects cardiomyocytes from hypoxia-associated cell damage by enhancing the expression of HIF- $1 \alpha$ via activating the $\mathrm{PI} 3 \mathrm{~K} / \mathrm{AKT} / \mathrm{mTOR}$ pathway [26]. Another study has shown the effects of Ginsenoside $\mathrm{Rg} 3$ in the protection of cardiomyocytes against apoptosis in myocardial ischemia via modulation of the AKT/eNOS and Bcl-2/Bax pathways [27]. Ginsenoside $\mathrm{Rg} 2$ has also been shown to improve cardiac function and amend myocardial fibrosis following myocardial infarction. This substance has suppressed collagen deposition in mice following myocardial infarction. Moreover, Ginsenoside $\mathrm{Rg} 2$ has decreased expressions of Collagen I (Col 1), Col 3, and alpha-smooth muscle actin through enhancing the activity of phosphorylated AKT in angiotensin II-induced cardiac fibroblasts. Since ginsenoside $\mathrm{Rg} 2$ can emend heart function and decrease cardiac fibrosis, it might be a putative medication for the prevention of ventricular remodeling following myocardial infarction [28]. Table 3 shows the effects of Ginsenosides in the treatment of cardiovascular diseases.

\section{Other non-neoplastic conditions}

20(R)-Ginsenoside Rg3 has been shown to ameliorate acetaminophen-induced liver damage in animal models through activating PI3K/AKT cascade. Pretreatment of mice with a certain dose of this substance has attenuated the effects of acetaminophen on levels of ALT, AST, TNF- $\alpha$, and IL- $1 \beta$. Moreover, Ginsenoside Rg3 could ameliorate the effects of acetaminophen on GSH and MDA levels as well as up-regulation of CYP2E1 and 4-HNE. Pretreatment of animals with this substance has also alleviated acetaminophen-induced apoptosis, necrosis, and inflammatory infiltration in the hepatic tissue [30]. Ginsenoside $\operatorname{Rg} 1$ could prevent starvation-induced muscle protein degradation via regulating the $\mathrm{AKT} / \mathrm{mTOR} / \mathrm{FoxO}$ axis in $\mathrm{C} 2 \mathrm{C} 12$ myotubes [31]. In addition, 20 (S)-ginsenoside $\mathrm{Rg} 3$ via regulating the AKT/mTOR/ FoxO3 axis could protect against myotube atrophy [7]. Ginsenoside $\mathrm{Rh} 2$ could decrease inflammatory responses in the lung tissue and lung injury via PI3K/AKT/mTOR and MEK/ ERK pathways [28]. On the other hand, Ginsenoside Rg1 via reducing the activity of the AKT/mTOR pathway could attenuate cognitive impairment and senescence of neural stem cells induced by D-galactose [32]. Table 4 shows the effects of Ginsenosides in the treatment of diverse pathological conditions.

\section{Neoplastic conditions}

\section{Leukemia}

20-(s)-ginsenoside $\operatorname{Rg} 3$ has been found to reduce the viability of human leukemic cells and induce apoptosis in these cells. Such effects have been accompanied by a 


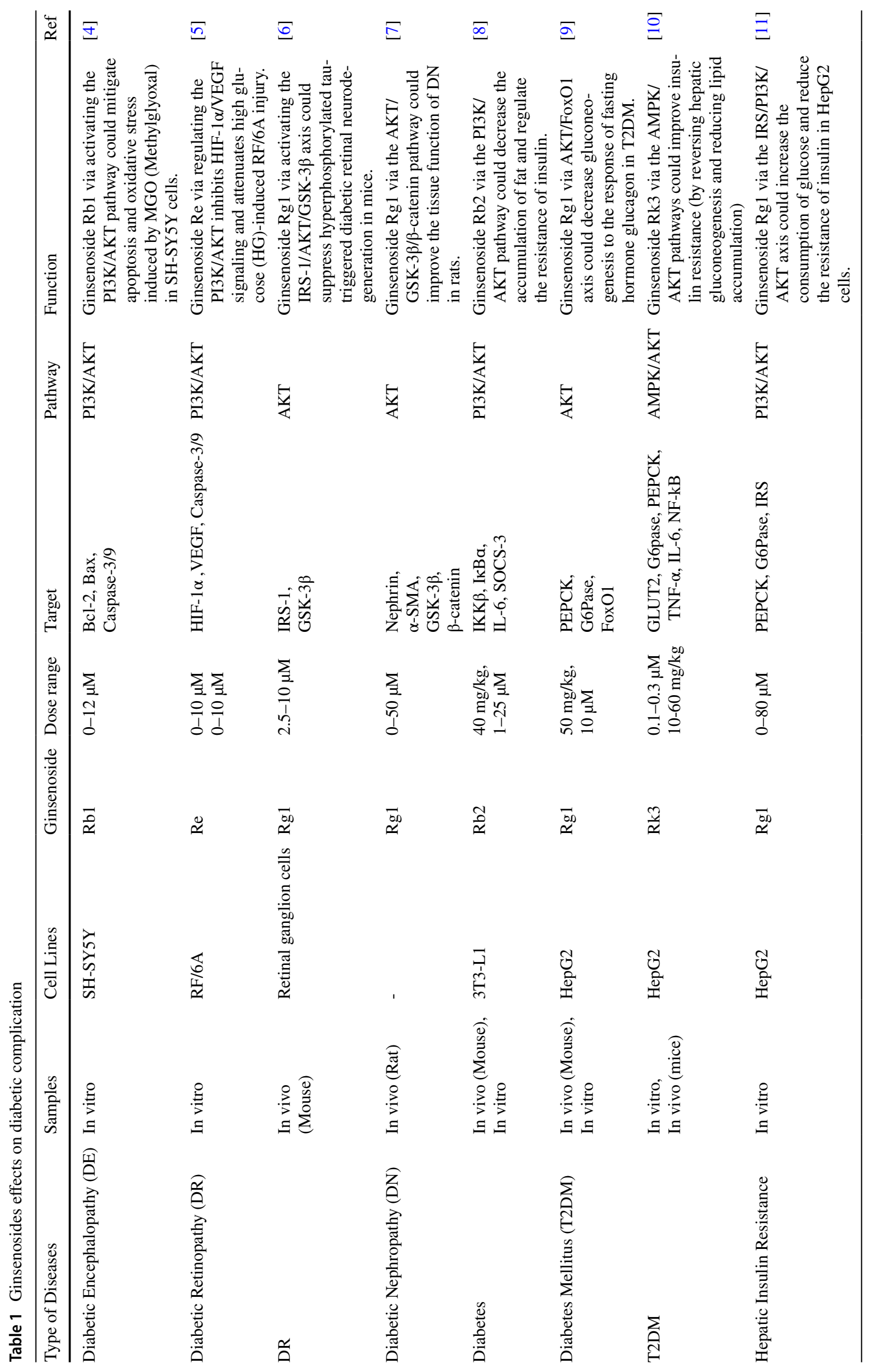




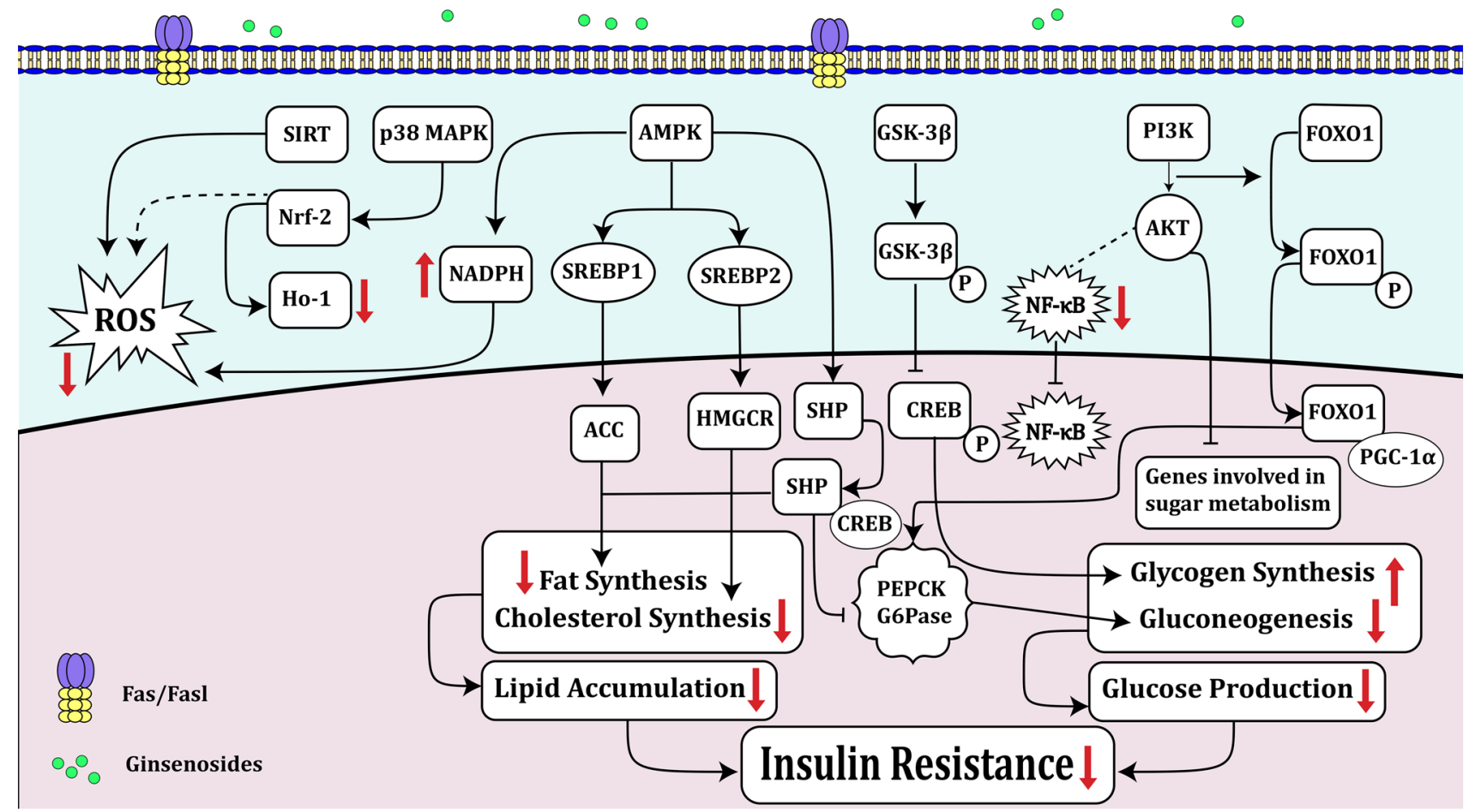

Fig. 2 Ginsenosides can affect the activity of PI3K/AKT, GSK-3 $\beta$, and AMPK pathways resulting in decreasing oxidative stress [4], inflammation, gluconeogenesis, glucose production, lipid accumulation, as well as insulin resistance [12]. There are three types of AKT substrates, GSK-3 $\beta$, FOXO1, and PGC- $1 \alpha$, that could be involved in liver glucose production. The activated PI3K/AKT pathway could participate in insulin metabolism and glucose uptake improvement via translocating GLUTs (glucose transporters, especially GLUT4) to the cell membrane and/or through enhancing glycogen synthesis that happens by phosphorylation of glycogen synthase kinase 3 (GSK-3 $\beta$ ) $[12,13]$. On the one hand, FOXO could regulate insulin responsiveness and glucose homeostasis [12]. Moreover, AMPK could decrease fat and cholesterol synthesis. Ginsenosides can also decrease insulin resistance. In addition, ginsenosides can inhibit ROS production via activating Nrf-2, HO-1, and AKT [14-16]. They can also inhibit the NF- $\mathrm{KB}$ signaling pathway and decrease inflammation via blocking the mRNA expression of pro-inflammatory mediators as well as cytokines, including TNF- $\alpha$, IL-1 $\beta$, iNOS, and COX-2 [14] significant decrease in the expression of several proteins from the PI3K/AKT cascade. Besides, 20-(s)-Ginsenoside $\mathrm{Rg} 3$ has increased activity of caspase- 3 and caspase- 9 . Therefore, this substance enhances apoptosis of human leukemic cells possibly via decreasing expression of PI3K/ AKT family proteins (Fig. 3). Besides, induction of caspase- 3 and caspase- 9 activity mediates induction of apoptosis, suggesting a possible application of this substance for the treatment of leukemia [42]. The anti-angiogenic impact of Ginsenoside $\operatorname{Rg} 3$ has also been assessed in patients with acute leukemia. Treatment of bone marrow stromal cells originated from patients with this type of leukemia with Ginsenoside $\mathrm{Rg} 3$ has led to inhibition of VEGF and HIF- $1 \alpha$ expressions. Moreover, Ginsenoside Rg3 could reduce expressions of HIF- $1 \alpha$ and VEGF (Fig. 3) in the serum samples of patients with acute leukemia. Functionally, this substance has reduced phosphorylation of AKT and ERK1/2 in bone marrow stem cells [43].

\section{Gastrointestinal cancers}

Ginsenoside Rh4 has shown a strong anticancer impact in esophageal cancer cells as well as animal models of this cancer. This substance suppresses the growth of cancer cells by arresting cancer cells at the G1 phase (Fig. 3). Moreover, Ginsenoside Rh4 suppresses aerobic glycolysis in this type of cancer by blocking the production of lactate, absorption of glucose, and synthesis of ATP. These effects lead to a reduction of extracellular acidification and oxygen consumption rates. AKT has been suggested as a putative target of Ginsenoside Rh4 through which inhibits aerobic glycolysis. Ginsenoside $\mathrm{Rh} 4$ has resulted in the deregulation of AKT, while insulin treatment has abrogated the suppressive impact of Ginsenoside Rh4 on aerobic glycolysis. On the contrary, AKT inhibitors have increased the suppressive impact of Ginsenoside Rh4 on aerobic glycolysis. Based on the results of molecular docking assays, Ginsenoside Rh4 binds to the interdomain 


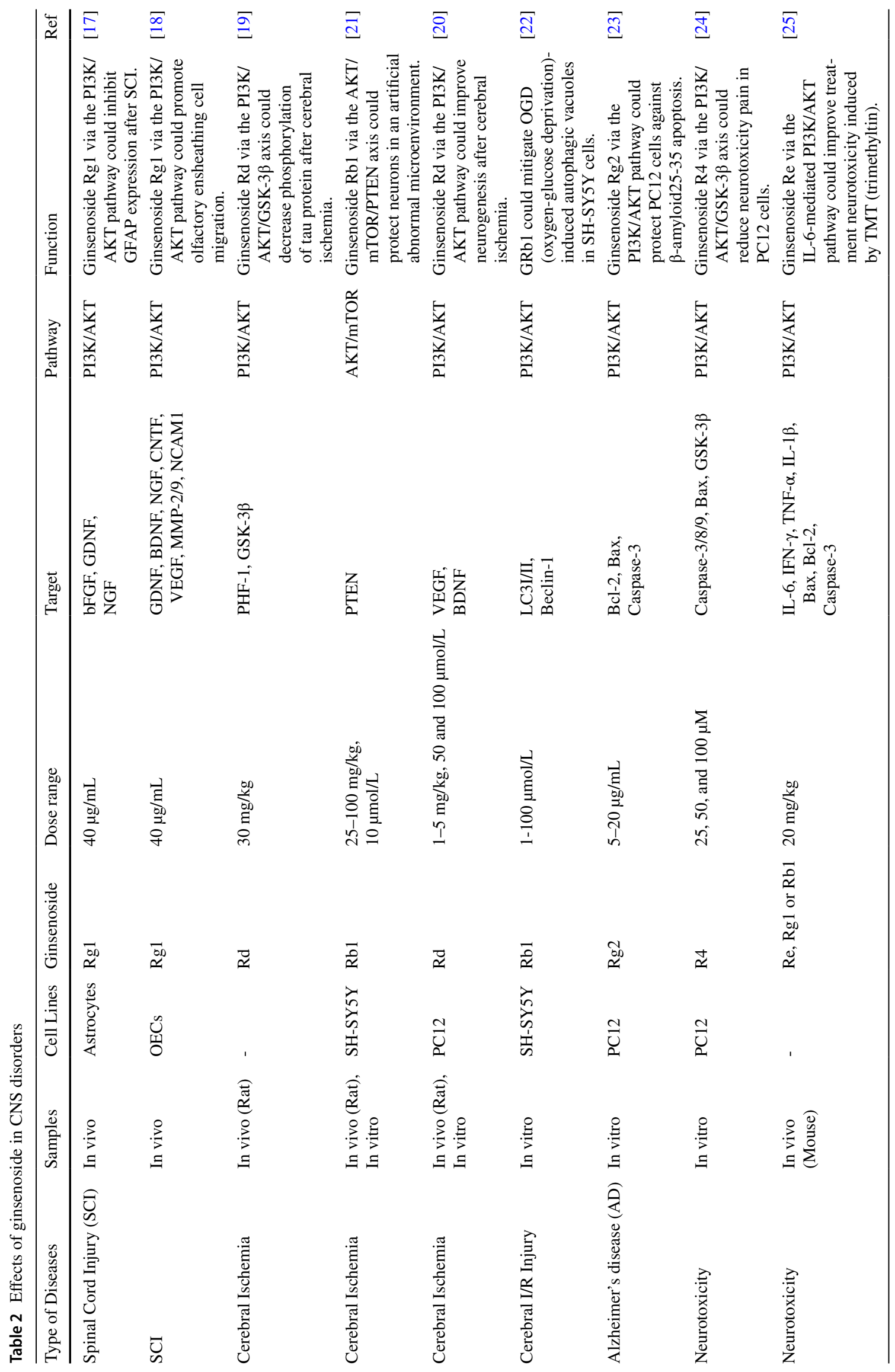


Table 3 Effects of ginsenoside on cardiovascular diseases

\begin{tabular}{|c|c|c|c|c|c|c|c|c|}
\hline Type of Diseases & Samples & Cell Lines & Ginsenoside & Dose range & Target & Pathway & Function & Ref \\
\hline $\begin{array}{l}\text { Myocardial } \\
\text { Ischemia } \\
(\mathrm{MI})\end{array}$ & $\begin{array}{l}\text { In vivo (Rat), } \\
\text { In vitro }\end{array}$ & $\mathrm{H} 9 \mathrm{c} 2$ & Rg1 & $\begin{array}{l}10 \mathrm{mg} / \mathrm{kg} \\
0-200 \mu \mathrm{M}\end{array}$ & $\begin{array}{l}\text { HIF-1 } \alpha, \\
\text { Bax, Bcl-2, } \\
\text { Caspase-3/9 }\end{array}$ & $\begin{array}{l}\text { PI3K/AKT/ } \\
\text { mTOR }\end{array}$ & $\begin{array}{l}\text { Ginsenoside Rg1 } \\
\text { via the PI3K/ } \\
\text { AKT/mTOR } \\
\text { pathway could } \\
\text { protect against } \\
\text { heart injury } \\
\text { induced by } \\
\text { hypoxia. }\end{array}$ & [26] \\
\hline MI & In vivo (Rat) & - & Rg3 & $0.1-100 \mu \mathrm{M}$ & $\begin{array}{l}\text { Caspase-3/9, } \\
\text { Bcl2, Bax, } \\
\text { eNOS }\end{array}$ & $\mathrm{AKT}$ & $\begin{array}{l}\text { Ginsenoside } \\
\text { Rg3 via the } \\
\text { AKT/eNOS } \\
\text { and Bcl-2/Bax } \\
\text { pathways could } \\
\text { protect cardiac } \\
\text { cells against } \\
\text { apoptosis in MI. }\end{array}$ & [27] \\
\hline MI & In vitro & $\mathrm{H} 9 \mathrm{c} 2$ & $\mathrm{Rb} 1$ & $\begin{array}{l}3.125-12.5 \mu \mathrm{g} / \\
\quad \mathrm{mL}\end{array}$ & $\begin{array}{l}\text { Caspase-3/8/9, } \\
\text { Bcl-2, Bax, Bid }\end{array}$ & $\begin{array}{l}\text { AKT, JNK, } \\
\text { ERK1/2 }\end{array}$ & $\begin{array}{l}\text { Ginsenoside } \\
\text { Rb1 via the } \\
\text { AKT, JNK } \\
\text { and ERK1/2 } \\
\text { pathways could } \\
\text { inhibit apoptosis } \\
\text { in cardiomyo- } \\
\text { cytes. }\end{array}$ & [29] \\
\hline MI & In vitro & NRCFs & $\operatorname{Rg} 2$ & $1-100 \mu \mathrm{M}$ & $\begin{array}{l}\text { Col1/3, } \\
\alpha-S M A\end{array}$ & $\mathrm{AKT}$ & $\begin{array}{l}\text { Ginsenoside Rg2 } \\
\text { via the AKT } \\
\text { pathway could } \\
\text { improve cardiac } \\
\text { function after } \\
\text { MI in NRCFs } \\
\text { cells. }\end{array}$ & [28] \\
\hline
\end{tabular}

region of AKT. Moreover, Ginsenoside Rh4 has decreased levels of PD-L1 through the AKT/mTOR pathway. Therefore, the anticancer impact of Ginsenoside Rh4 in esophageal cancer is exerted through inhibition of aerobic glycolysis and PD-L1 expression [44].

20(S)-Ginsenoside $\operatorname{Rg} 3$ has been shown to enhance the anticancer effects of Sorafenib in hepatocellular carcinoma. This kind of treatment has resulted in the up-regulation of levels of PTEN, Bax, and cleaved caspase-3, while downregulation of levels of phosphorylated PDK1 and phosphorylated Ak3. Notably, in vivo experiments have shown a decrease in tumor volume and weight following administration of the combination of Sorafenib and 20(S)-Ginsenoside $\mathrm{Rg} 3$. Therefore, this study has shown the synergism between 20(S)-Ginsenoside $\operatorname{Rg} 3$ and Sorafenib in the treatment of hepatocellular carcinoma through modulation of PTEN/ AKT signaling [45]. Another study has shown the effects of the combination of CA4P and Ginsenoside Rd on the reduction of HIF-1 $\alpha$ expression in hepatocellular carcinoma cells via the PI3K/AKT/mTOR pathway [46]. Table 5 shows the effects of Ginsenoside in the treatment of gastrointestinal cancers.

\section{Gynecologic cancers}

Two studies have demonstrated the beneficial effects of Ginsenosides in the treatment of gynecological cancers. First, 20(s)-ginsenoside $\operatorname{Rg} 3$ has been shown to reduce viability and induce apoptosis of ovarian cancer cells in a dose- and time-dependent manner. This substance could down-regulate expressions of PI3K/AKT (Fig. 3) and IAP family proteins. Moreover, it could activate caspase-3 and -9 [50]. Another study has demonstrated the effects of Ginsenoside Rh2 in the inhibition of proliferation and migration of cervical cancer cells through modulation of the AKT/GSK-3 $\beta$ axis [51]. Table 6 shows the outlines of these studies.

\section{Breast cancer}

Ginsenoside Rd has been shown to inhibit VEGF-induced migration, tube formation, and proliferation of HUVEC cells in a dose-dependent manner. Moreover, Ginsenoside Rd could abrogate VEGF-induced emergence of the vessels from aortic rings, and suppress vessel construction in vivo. In both normoxia and hypoxia, Ginsenoside Rd has 


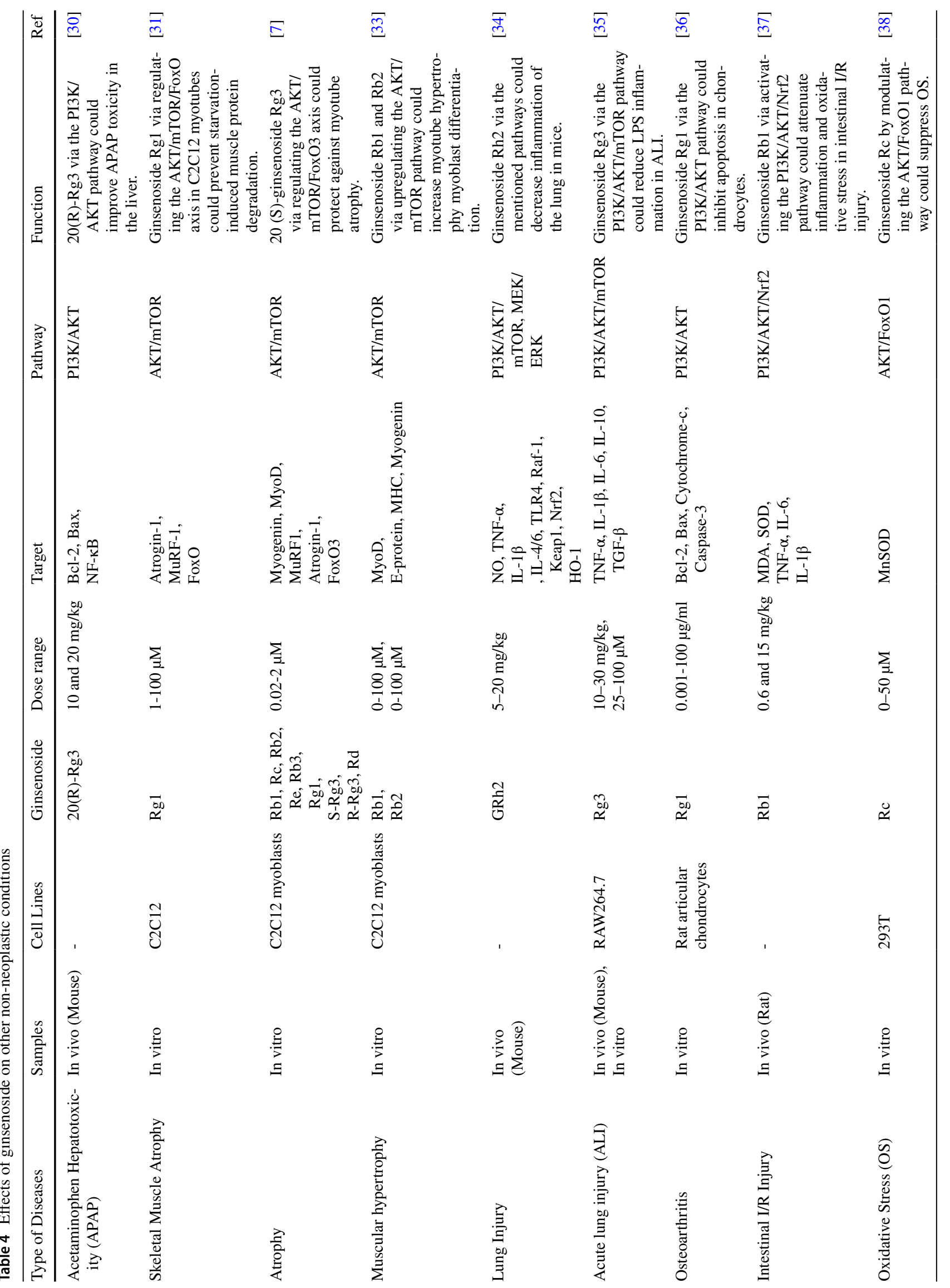




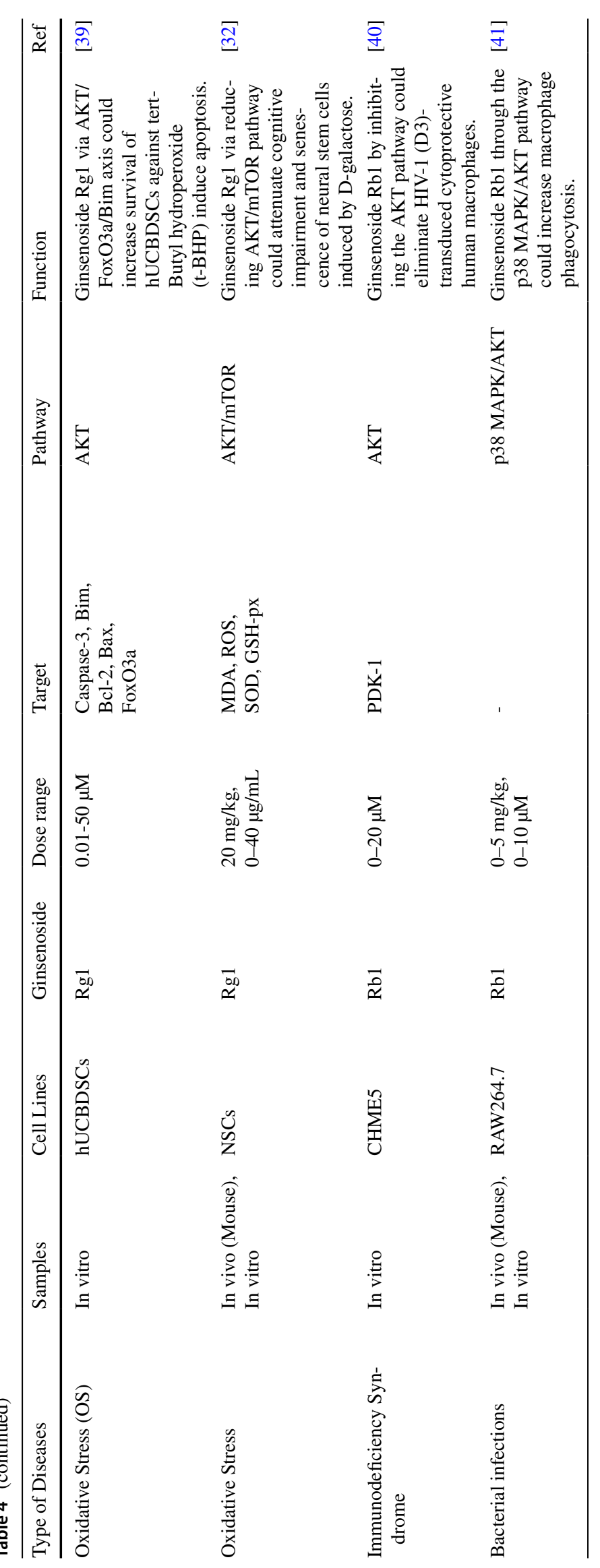




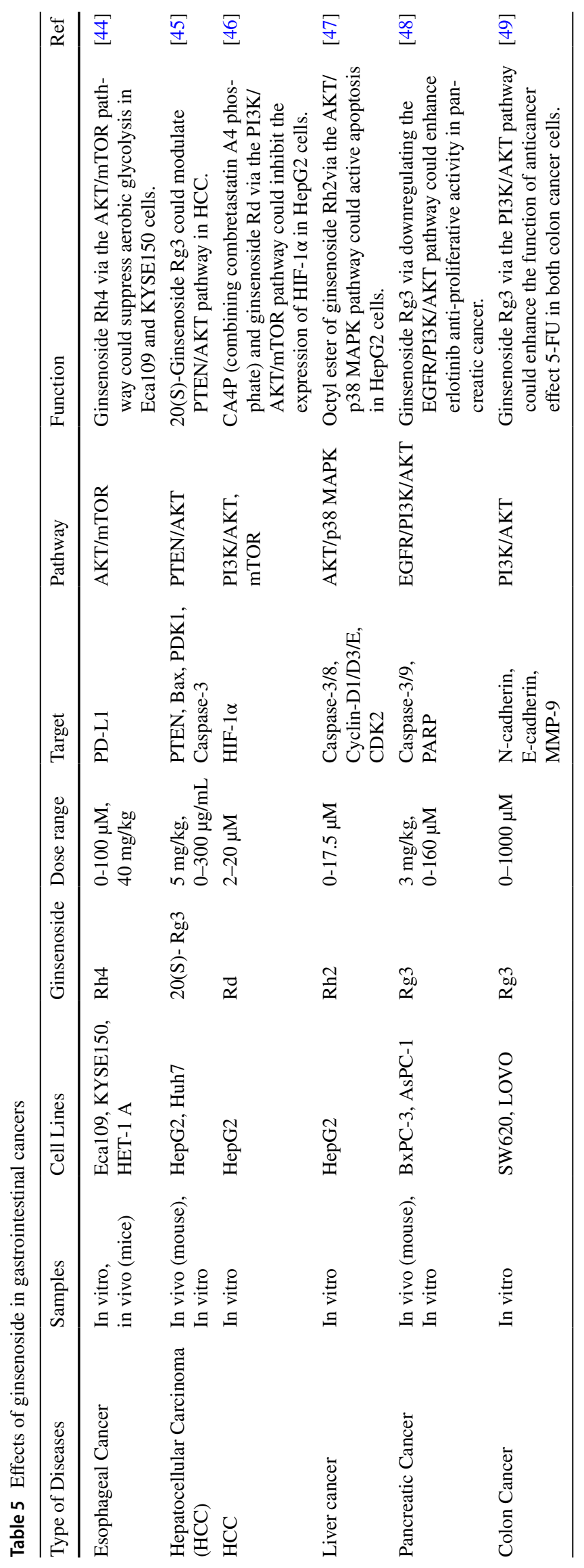


Table 6 Effects of ginsenoside in gynecologic cancers

\begin{tabular}{|c|c|c|c|c|c|c|c|c|}
\hline Type of cancer & Samples & Cell Lines & Ginsenoside & Dose range & Target & Pathway & Function & Ref \\
\hline Ovarian Cancer (OC) & In vitro & HO-8910 & 20(S)-Rg3 & $0-100 \mu \mathrm{g} / \mathrm{mL}$ & $\begin{array}{l}\text { Caspase-3/9, Bcl-2, } \\
\text { Bax, XIAP, cIAP1/2 }\end{array}$ & PI3K/AKT & $\begin{array}{l}\text { 20(s)-ginsenoside Rg3 } \\
\text { via the PI3K/AKT } \\
\text { and XIAP pathways } \\
\text { could improve apopto- } \\
\text { sis in human OC } \\
\text { HO- } 8910 \text { cells. }\end{array}$ & [50] \\
\hline Cervical Cancer (CC) & In vitro & HeLa & $20(\mathrm{~S})-\mathrm{Rh} 2$ & $10-50 \mu \mathrm{M}$ & $\begin{array}{l}\text { Ncadherin, GSK-3 } \beta \text {, } \\
\text { Vimentin, Ecadherin, } \\
\text { Zeb1, Snail-1 }\end{array}$ & AKT & $\begin{array}{l}\text { Rh2 via the AKT/ } \\
\text { GSK-3 } \beta \text { axis could } \\
\text { inhibit cell prolifera- } \\
\text { tion and migration of } \\
\text { HeLa cells. }\end{array}$ & [51] \\
\hline
\end{tabular}

inhibited VEGF-associated induction of AKT/ mTOR cascade in HUVECs. Intraperitoneal administration of Ginsenoside Rd to xenograft model of breast cancer has resulted in the reduction of tumor volume and weight and decrease in tumor angiogenesis. Moreover, Ginsenoside Rd has suppressed proliferation, enhanced apoptosis inhibited AKT/ mTOR/P70S6 kinase cascade in breast cancer [52]. The molecular mechanism of the anti-proliferative and proapoptotic impact of Ginsenosides Rg3 in breast cancer cells has also been explored in a cell line that has constitutive activation of NF- $\mathrm{KB}$ and p53 mutation. Ginsenoside Rg3 has suppressed DNA binding and transcriptional activity of NF-кВ. These impacts have been exerted through inhibition of IKK $\beta$ function, destruction of $\mathrm{I} \kappa \mathrm{B} \alpha$, and consequent nuclear translocation of the p65 subunit of NF-кB. Ginsenoside Rg3 has increased apoptosis in MDA-MB-231 cells through suppressing NF- $\mathrm{B}$ cascade via inactivating ERK and AKT (Fig. 3) and destabilizing mutant p53 [53]. Table 7 shows the effects of Ginsenosides in the treatment of breast cancer.

\section{Brain tumors}

Ginsenoside Rh2 has been shown to reduce the viability and proliferation of glioma cells via modulating AKT [56]. Moreover, this substance has decreased the invasiveness of glioblastoma cells in a dose-dependent manner as demonstrated in scratch wound healing and Transwell cell migration assays. Besides, the suppressive impact of Ginsenoside $\mathrm{Rh} 2$ on cell migration has been found to be exerted via down-regulation of MMP-13. Ginsenoside Rh2 suppresses the expression of MMP13 via the PI3k/AKT pathway. Therefore, Ginsenoside Rh2 can inhibit migration of glioblastoma via suppressing AKT-associated MMP13 activation [57].

Table 7 Effects of ginsenoside in breast cancer

\begin{tabular}{|c|c|c|c|c|c|c|c|}
\hline Samples & Cell Lines & Ginsenoside & Dose range & Target & Pathway & Function & Ref \\
\hline $\begin{array}{l}\text { In vivo } \\
\text { (Rat, Mouse), } \\
\text { In vitro }\end{array}$ & $\begin{array}{l}\text { HUVECs, } \\
\text { MDA-MB-231 }\end{array}$ & $\mathrm{Rd}$ & $\begin{array}{l}1-10 \mathrm{mg} / \mathrm{kg}, \\
0-50 \mu \mathrm{M}\end{array}$ & $\begin{array}{l}\text { HIF-1 } \alpha, \text { Bax, Bcl-2, } \\
\text { Caspase-3, p70S6K }\end{array}$ & $\mathrm{AKT} / \mathrm{mTOR}$ & $\begin{array}{l}\text { Ginsenoside Rd via regulat- } \\
\text { ing the AKT/mTOR/ } \\
\text { p70S6K axis could sup- } \\
\text { press breast tumor growth } \\
\text { and angiogenesis. }\end{array}$ & {$[52]$} \\
\hline In vitro & MDA-MB-231 & $\operatorname{Rg} 3$ & $0-30 \mu \mathrm{M}$ & $\begin{array}{l}\text { NF-кВ, p65, } \\
\text { ІкB } \alpha, \text { IKK } \beta, \text { p53 }\end{array}$ & $\begin{array}{l}\text { ERK, } \\
\text { AKT }\end{array}$ & $\begin{array}{l}\text { Ginsenoside Rg3 via the } \\
\text { ERK/AKT pathway could } \\
\text { affect apoptosis by sup- } \\
\text { pressing the activation of } \\
\text { NF-кB in human BCa. }\end{array}$ & {$[53]$} \\
\hline In vitro & $\mathrm{MCF}-7$ & Rk1 & $0-160 \mu \mathrm{M}$ & $\begin{array}{l}\text { p21, p53, Cyclin-A, CDK2, } \\
\text { Bax, Bcl-2, Cytochrome-C, } \\
\text { Caspase-3/8/9, PTEN }\end{array}$ & $\begin{array}{l}\text { PI3K/AKT, } \\
\text { mTOR }\end{array}$ & $\begin{array}{l}\text { In MCF-7 cells, ginsenoside } \\
\text { Rk1 via ROS-mediated } \\
\text { PTEN/PI3K/AKT/mTOR } \\
\text { pathway could induce cell } \\
\text { death. }\end{array}$ & {$[54]$} \\
\hline In vivo (Mouse) & $\mathrm{MCF}-7$ & $\operatorname{Rg} 5$ & $10-20 \mathrm{mg} / \mathrm{kg}$ & $\begin{array}{l}\text { Caspase-8/9/3, Bax, } \\
\text { Cytochrome-C, } \\
\text { PARP, Bcl-2 }\end{array}$ & PI3K/AKT & $\begin{array}{l}\text { Ginsenoside Rg5 via the } \\
\text { PI3K/AKT pathway could } \\
\text { induce apoptosis and } \\
\text { autophagy in BCa. }\end{array}$ & {$[55]$} \\
\hline
\end{tabular}




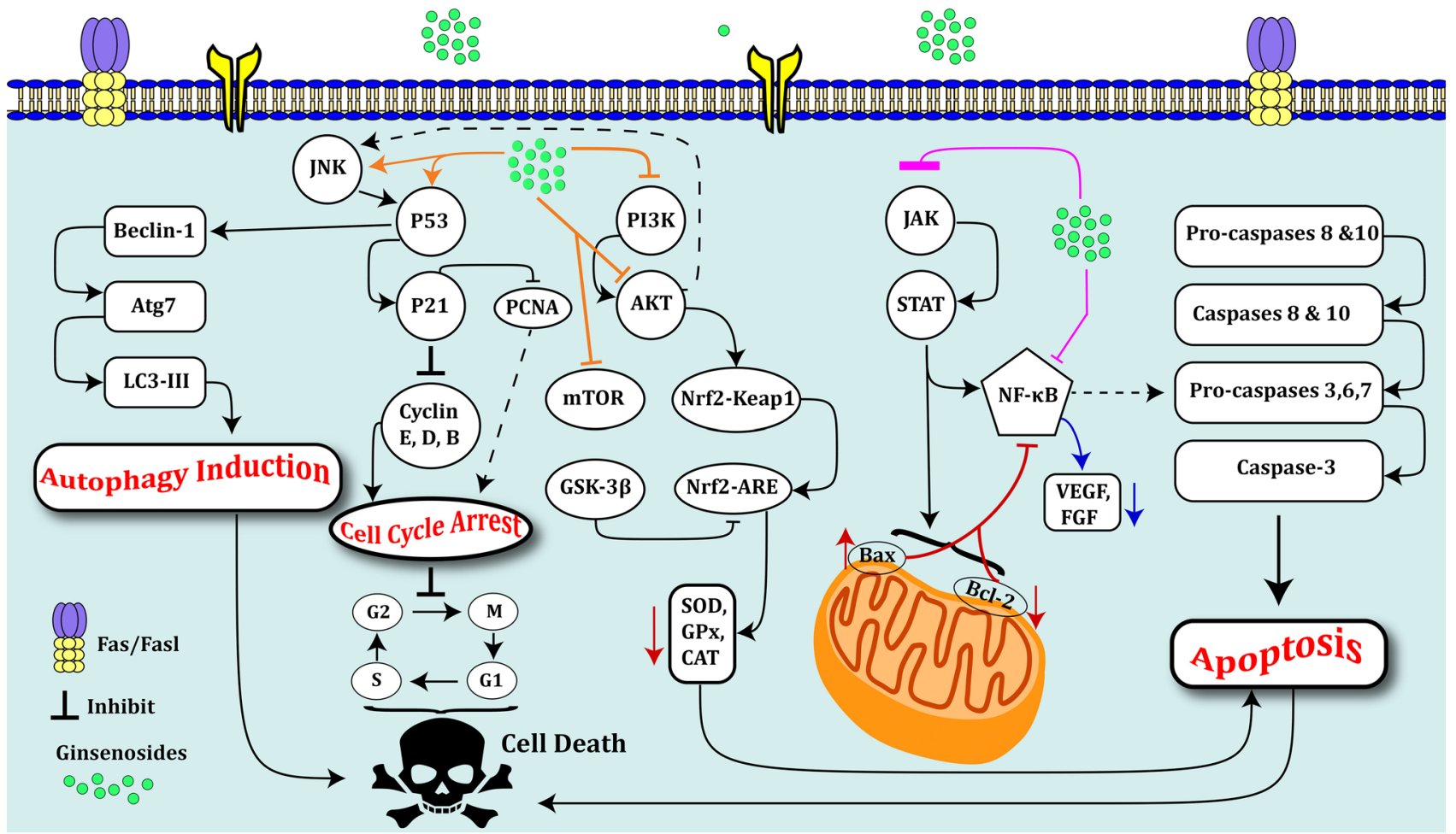

Fig. 3 Several studies have shown that ginsenosides have anti-tumor activity. In tumor cells, ginsenosides could induce exogenous apoptosis via enhancing the expression of TRAILs, p53, Fas/FasL, resulting in the activation of caspase cascades (Pro-caspase-8-caspase-3) [61]. Ginsenosides could regulate the JAK/STAT pathway involved in immune regulatory processes. They have regulatory roles on P53, Fas/FasL, and Bax [62]. Indeed, ginsenosides via blocking JAK1/ STAT3 could decrease the expression of STAT3 target genes, including survivin, Bcl-2, Bcl-xL. Therefore, they could increase apoptosis

\section{Other cancers}

A recent experiment in osteosarcoma cells has shown that ginsenoside $\mathrm{Rh} 2$ significantly suppresses the viability of U20S cells in a dose- and time-dependent manner, and inhibits their migration. Moreover, the effects of this substance on the induction of apoptosis in U20S cells have been verified through the conduction of TUNEL, DAPI, annexin V/PI, and JC-1 assays. Ginsenoside Rh2 can also decrease expression of Bcl-2, caspase 3, and caspase 9, and enhance Bax levels in osteosarcoma cells. Functionally, ginsenoside $\mathrm{Rh} 2$ enhances apoptosis of U20S cells through increasing activity of MAPK pathway and suppressing activities of PI3K/AKT/ mTOR and NF-кB pathways in osteosarcoma cells (Fig. 3). Thus, ginsenoside $\mathrm{Rh} 2$ exerts anticancer effects in osteosarcoma through influencing the activity of MAPK, PI3K/ AKT/mTOR, and NF-кB pathways [58]. Ginsenoside Rg3 via inhibiting the PI3K/AKT pathway could exert antitumor effects in lung cancer [59]. Finally, Ginsenoside Rg3 via ERK and AKT pathways could inhibit angiogenesis of in tumor cells via inhibiting the mentioned pathway [62, 63]. Interestingly, they could inhibit NF-кB signaling by regulating Bax/Bcl-2 expression, resulting in the inhibition of angiogenesis [64]. Ginsenosides also via blocking the PI3K/AKT/mTOR could inhibit the proliferation of cancer cells and induce apoptosis [48, 65]. Ginsenosides by decreasing the expression of some cell cycle proteins including Cyclin-B1 could block tumor cell cycles [66, 67]. Ginsenosides by upregulating the expression of LC3-II, Beclin-1, and Atg7 could also induce autophagy, resulting in tumor cell death $[68,69]$

melanoma and inhibit the growth of B16 cells [60]. Table 8 shows the effects of Ginsenosides in diverse cancers.

\section{Discussion}

Ginsenosides are a group of substances extracted from plants. Although they have been used in traditional medicine for a long time, the underlying mechanisms of their therapeutic effects are being illustrated just recently. Diabetes and CNS disorders are two types of disorders in which the therapeutic effects of Ginsenosides are extensively appraised. The PI3K/AKT signaling has been shown to be the most appreciated target of different Ginsenosides. The beneficial effects of these substances in the treatment of diabetic complications, SCI, cerebral/myocardial ischemia, and several other non-neoplastic conditions are exerted through activating this pathway. On the other hand, experiments in diverse cancer cell lines have shown the inhibitory effects of Ginsenosides on the PI3K/AKT pathway. 
Table 8 Effects of Ginsenoside in diverse cancers

\begin{tabular}{|c|c|c|c|c|c|c|c|c|}
\hline Type of cancer & Samples & Cell Lines & Ginsenoside & Dose range & Target & Pathway & Function & Ref \\
\hline $\begin{array}{l}\text { Osteosarcoma } \\
\text { (OS) }\end{array}$ & In vitro & U20S & Rh2 & $8-80 \mu \mathrm{M}$ & $\begin{array}{l}\text { Bcl-2, Bax, } \\
\text { NF-кB, Cas- } \\
\text { pase-3/9 }\end{array}$ & $\begin{array}{l}\text { PI3K/AKT/ } \\
\text { mTOR, } \\
\text { MAPK }\end{array}$ & $\begin{array}{l}\text { Ginsenoside } \\
\text { Rh2 via } \\
\text { NF-KB, } \\
\text { MAPK, and } \\
\text { PI3K/AKT/ } \\
\text { mTOR } \\
\text { pathways } \\
\text { could suppress } \\
\text { proliferation } \\
\text { and migration } \\
\text { in U20S cells. }\end{array}$ & [58] \\
\hline Lung Cancer & $\begin{array}{l}\text { In vivo (Mouse), } \\
\text { In vitro }\end{array}$ & $\begin{array}{l}\text { A549, } \\
\text { H23 }\end{array}$ & $\operatorname{Rg} 3$ & $\begin{array}{l}20 \mathrm{mg} / \mathrm{kg} \\
0-200 \mu \mathrm{M}\end{array}$ & - & PI3K/AKT & $\begin{array}{l}\text { Ginsenoside } \\
\text { Rg3 via inhib- } \\
\text { iting the PI3K/ } \\
\text { AKT pathway } \\
\text { could exert } \\
\text { antitumor } \\
\text { effects in lung } \\
\text { cancer. }\end{array}$ & [59] \\
\hline $\begin{array}{l}\text { Advanced } \\
\text { Metastatic } \\
\text { Melanoma }\end{array}$ & $\begin{array}{l}\text { In vitro, } \\
\text { In vivo (Mouse) }\end{array}$ & B16 & $\operatorname{Rg} 3$ & $\begin{array}{l}1-15 \mu \mathrm{g} / \mathrm{mL} \\
0.3-3 \mathrm{mg} / \mathrm{kg}\end{array}$ & $\begin{array}{l}\text { VEGF, } \\
\text { HIF-1 } \alpha \text {, } \\
\text { MMP-2/9 }\end{array}$ & ERK/AKT & $\begin{array}{l}\text { Ginsenoside } \\
\text { Rg3 via ERK } \\
\text { and AKT } \\
\text { pathways } \\
\text { could inhibit } \\
\text { the angio- } \\
\text { genesis of } \\
\text { melanoma } \\
\text { and inhibit the } \\
\text { growth of B16 } \\
\text { cells. }\end{array}$ & [60] \\
\hline- & In vitro & $\begin{array}{l}\text { SW620, LS513, } \\
\text { OVCAR8- } \\
\text { DXR, } \\
\text { A549-DXR }\end{array}$ & Rp1 & $\begin{array}{l}0-5 \mu \mathrm{M} \\
0-30 \mu \mathrm{M}\end{array}$ & $\begin{array}{l}\text { SIRT1, } \\
\text { PARP }\end{array}$ & AKT & $\begin{array}{l}\text { A combination } \\
\text { of ginseno- } \\
\text { side Rp1 and } \\
\text { actinomycin D } \\
\text { via the AKT/ } \\
\text { SIRT1 axis } \\
\text { could reduce } \\
\text { drug resist- } \\
\text { ance. }\end{array}$ & [70] \\
\hline
\end{tabular}

HIF-1 $\alpha$, Bax, Bcl-2, Caspase-3/8/9, p70S6K, NF-кB, p65, IкB $\alpha$, IKK $\beta$, p53, p21, Cyclin-A, CDK2, Cytochrome $\mathrm{C}$ and PTEN are other molecules whose expressions are affected by Ginsenosides.

In addition to the observed controversy about the effect of Ginsenosides on the PI3K/AKT signaling, the effects of Ginsenosides on the expression of HIF-1 $\alpha$ and VEGF are controversial. Ginsenoside Re has been shown to enhance the expression of HIF-1 $\alpha$ in the cytoplasm but reduce its nuclear levels [5]. Moreover, Ginsenoside Rg1 has been reported to increase the expression of HIF-1 $\alpha$ [26]. On the other hand, treatment of leukemic bone marrow stromal cells with Ginsenoside Rg3 has led to inhibition of VEGF and HIF-1 $\alpha$ expressions [43]. The possible impact of the underlying pathological conditions and different effects of various Ginsenosides or even different doses of these substances on the expression of genes should be assessed in future studies. In addition to the regulatory effects of Ginsenosides on the activity of cancer-related pathways, suppression of aerobic glycolysis by these substances can be regarded as a possible route of anticancer effects of these substances. Moreover, Ginsenosides can enhance the activity of other anticancer drugs including both herbal medicines and targeted therapeutic options on tumor cells indicating their synergisms with a wide range of therapeutic modalities. A combination of Ginsenosides with other anticancer drugs might also reduce resistance of cancer cells to cytotoxic effects of these drugs. 


\section{Conclusion}

The above-mentioned studies have mostly assessed the effects of Ginsenosides in cell lines or animal models, lacking evidence from human subjects. Conduction of well-designed studies in human subjects is required for the identification of the proper dose of Ginsenosides in each pathologic condition. Moreover, future studies should identify appropriate markers for the prediction of the response of cancer cells to Ginsenosides.

Finally, based on the observed effects of Ginsenosides on the production of ROS, these agents may be regarded as preventive strategies against the initiation of cancer. However, this field has been little explored by researchers.

\section{Acknowledgements Not applicable.}

Author contributions SGF wrote the manuscript and revised it. MT designed and supervised the study. BMH, NB, HS, SMFH, SFT and SAA collected the data and designed the tables and figures. All authors read and approved the submitted manuscript.

Funding Open Access funding enabled and organized by Projekt DEAL. Not applicable.

Data availability Data sharing not applicable to this article as no datasets were generated or analysed during the current study.

\section{Declarations}

Conflict of interest The authors declare they have no conflict of interest.

Consent to participant Not applicable.

Ethical approval Not applicable.

Open Access This article is licensed under a Creative Commons Attribution 4.0 International License, which permits use, sharing, adaptation, distribution and reproduction in any medium or format, as long as you give appropriate credit to the original author(s) and the source, provide a link to the Creative Commons licence, and indicate if changes were made. The images or other third party material in this article are included in the article's Creative Commons licence, unless indicated otherwise in a credit line to the material. If material is not included in the article's Creative Commons licence and your intended use is not permitted by statutory regulation or exceeds the permitted use, you will need to obtain permission directly from the copyright holder. To view a copy of this licence, visit http://creativecommons.org/licenses/by/4.0/.

\section{References}

1. Attele AS, Wu JA, Yuan CS (1999) Ginseng pharmacology: multiple constituents and multiple actions. Biochem Pharmacol 58(11):1685-1693

2. Fuzzati N (2004) Analysis methods of ginsenosides. J Chromatogr B 812:119-1331
3. Lü J-M, Yao Q, Chen C (2009) Ginseng compounds: an update on their molecular mechanisms and medical applications. Curr Vasc Pharmacol 7(3):293-302

4. Nan F, Sun G, Xie W, Ye T, Sun X, Zhou P et al (2019) Ginsenoside $\mathrm{Rb} 1$ mitigates oxidative stress and apoptosis induced by methylglyoxal in SH-SY5Y cells via the PI3K/Akt pathway. Mol Cell Probes 48:101469

5. Xie W, Zhou P, Qu M, Dai Z, Zhang X, Zhang C et al (2020) Ginsenoside Re attenuates high glucose-induced RF/6A injury via regulating $\mathrm{PI} 3 \mathrm{~K} / \mathrm{AKT}$ inhibited HIF-1 $\alpha /$ VEGF signaling pathway. Front Pharmacol 11:695

6. Ying Y, Zhang Y-l, Ma C-j, Li M-q, Tang C-y, Yang Y-f et al (2019) Neuroprotective effects of ginsenoside Rg1 against hyperphosphorylated tau-induced diabetic retinal neurodegeneration via activation of IRS-1/akt/gsk3 $\beta$ signaling. J Agric Food Chem 67(30):8348-8360

7. Zhu S, Liu X, Xue M, Li Y, Cai D, Wang S et al (2020) 20 (S)-ginsenoside $\mathrm{Rh} 2$ induces caspase-dependent promyelocytic leukemia-retinoic acid receptor A degradation in NB4 cells via Akt/Bax/caspase 9 and $\mathrm{TNF}-\alpha /$ caspase 8 signaling cascades. $\mathbf{J}$ Ginseng Res 45:295

8. Dai S, Hong Y, Xu J, Lin Y, Si Q, Gu X (2018) Ginsenoside $\mathrm{Rb} 2$ promotes glucose metabolism and attenuates fat accumulation via AKT-dependent mechanisms. Biomed Pharmacother 100:93-100

9. Liu Q, Zhang F-G, Zhang W-S, Pan A, Yang Y-L, Liu J-F et al (2017) Ginsenoside Rg1 inhibits glucagon-induced hepatic gluconeogenesis through Akt-FoxO1 interaction. Theranostics 7(16):4001

10. Liu Y, Deng J, Fan D (2019) Ginsenoside Rk3 ameliorates highfat-diet/streptozocin induced type 2 diabetes mellitus in mice via the AMPK/Akt signaling pathway. Food Funct 10(5):2538-2551

11. Mo J, Zhou Y, Yang R, Zhang P, He B, Yang J et al (2019) Ginsenoside $\mathrm{Rg} 1$ ameliorates palmitic acid-induced insulin resistance in HepG2 cells in association with modulating Akt and JNK activity. Pharmacol Rep 71(6):1160-1167

12. Shao J-W, Jiang J-L, Zou J-J, Yang M-Y, Chen F-M, Zhang Y-J et al (2020) Therapeutic potential of ginsenosides on diabetes: from hypoglycemic mechanism to clinical trials. J Funct Foods 64:103630

13. Alolga RN, Nuer-Allornuvor GF, Kuugbee ED, Yin X, Ma G (2020) Ginsenoside $\operatorname{Rg} 1$ and the control of inflammation implications for the therapy of type 2 diabetes: a review of scientific findings and call for further research. Pharmacol Res 152:104630

14. Im D-S (2020) Pro-Resolving Effect of ginsenosides as an anti-inflammatory mechanism of Panax ginseng. Biomolecules 10(3):444

15. Leung KW, Wong AS-T (2010) Pharmacology of ginsenosides: a literature review. Chin Med 5(1):1-7

16. Kim CY, Kang B, Suh HJ, Choi H-S (2018) Red ginseng-derived saponin fraction suppresses the obesity-induced inflammatory responses via Nrf2-HO-1 pathway in adipocyte-macrophage coculture system. Biomed Pharmacother 108:1507-1516

17. Xu L, Tang Y-Y, Ben X-L, Cheng M-H, Guo W-X, Liu Y et al (2020) Ginsenoside Rg1-induced activation of astrocytes promotes functional recovery via the PI3K/Akt signaling pathway following spinal cord injury. Life Sci 252:117642

18. Tang Y-Y, Guo W-X, Lu Z-F, Cheng M-H, Shen Y-X, Zhang Y-Z (2017) Ginsenoside Rg1 promotes the migration of olfactory ensheathing cells via the PI3K/Akt pathway to repair rat spinal cord injury. Biol Pharm Bull 40(10):1630-1637

19. Zhang X, Shi M, Ye R, Wang W, Liu X, Zhang G et al (2014) Ginsenoside Rd attenuates tau protein phosphorylation via the PI3K/AKT/GSK-3 $\beta$ pathway after transient forebrain ischemia. Neurochem Res 39(7):1363-1373 
20. Liu X-y, Zhou X-y, Hou J-c, Zhu H, Wang Z, Liu J-x et al (2015) Ginsenoside Rd promotes neurogenesis in rat brain after transient focal cerebral ischemia via activation of PI3K/Akt pathway. Acta Pharmacol Sin 36(4):421-428

21. Guo Y, Wang L-P, Li C, Xiong Y-X, Yan Y-T, Zhao L-Q et al (2018) Effects of Ginsenoside Rb1 on expressions of phosphorylation Akt/phosphorylation mTOR/phosphorylation PTEN in artificial abnormal hippocampal microenvironment in rats. Neurochem Res 43(10): 1927-1937

22. Luo T, Liu G, Ma H, Lu B, Xu H, Wang Y et al (2014) Inhibition of autophagy via activation of PI3K/Akt pathway contributes to the protection of ginsenoside $\mathrm{Rb} 1$ against neuronal death caused by ischemic insults. Int J Mol Sci 15(9):15426-15442

23. Cui J, Wang J, Zheng M, Gou D, Liu C, Zhou Y (2017) Ginsenoside $\mathrm{Rg} 2$ protects $\mathrm{PC} 12$ cells against $\beta$-amyloid25-35-induced apoptosis via the phosphoinositide 3-kinase/Akt pathway. Chemico-Biol Interact 275:152-161

24. Luo Y, Jiang Y, He Y, Shen T, Ji L, Li F et al (2020) Vinaginsenoside R4 from Panax ginseng leaves alleviates 6-OHDAinduced neurotoxicity in PC12 cells via the PI3K/Akt/GSK-3 $\beta$ signaling pathway. J Agric Food Chem 68:51

25. Tu T-HT, Sharma N, Shin E-J, Tran H-Q, Lee YJ, Jeong JH et al (2017) Ginsenoside Re protects trimethyltin-induced neurotoxicity via activation of IL-6-mediated phosphoinositol 3-kinase/ Akt signaling in mice. Neurochem Res 42(11):3125-3139

26. Qin L, Fan S, Jia R, Liu Y (2018) Ginsenoside Rg1 protects cardiomyocytes from hypoxia-induced injury through the PI3K/ AKT/mTOR pathway. Die Pharm 73(6):349-355

27. Wang Y, Hu Z, Sun B, Xu J, Jiang J, Luo M (2015) Ginsenoside $\mathrm{Rg} 3$ attenuates myocardial ischemia/reperfusion injury via Akt/endothelial nitric oxide synthase signaling and the B-cell lymphoma/B-cell lymphoma-associated X protein pathway. Mol Med Rep 11(6):4518-4524

28. Li X, Xiang N, Wang Z (2020) Ginsenoside Rg2 attenuates myocardial fibrosis and improves cardiac function after myocardial infarction via AKT signaling pathway. Biosci Biotechnol Biochem 84(11):2199-2206

29. Ai Q, Sun G, Luo Y, Dong X, Hu R, Meng X et al (2015) Ginsenoside $\mathrm{Rb} 1$ prevents hypoxia-reoxygenation-induced apoptosis in $\mathrm{H} 9 \mathrm{c} 2$ cardiomyocytes via an estrogen receptordependent crosstalk among the Akt, JNK, and ERK 1/2 pathways using a label-free quantitative proteomics analysis. RSC Adv 5(33):26346-26363

30. Zhou Y-d, Hou J-g, Liu W, Ren S, Wang Y-p, Zhang R et al (2018) 20 (R)-ginsenoside $\mathrm{Rg} 3$, a rare saponin from red ginseng, ameliorates acetaminophen-induced hepatotoxicity by suppressing PI3K/AKT pathway-mediated inflammation and apoptosis. Int Immunopharmacol 59:21-30

31. Li F, Li X, Peng X, Sun L, Jia S, Wang P et al (2017) Ginsenoside $\mathrm{Rg} 1$ prevents starvation-induced muscle protein degradation via regulation of AKT/mTOR/FoxO signaling in $\mathrm{C} 2 \mathrm{C} 12$ myotubes. Exp Therapeut Med 14(2):1241-1247

32. Chen L, Yao H, Chen X, Wang Z, Xiang Y, Xia J et al (2018) Ginsenoside Rg1 decreases oxidative stress and down-regulates $\mathrm{Akt} / \mathrm{mTOR}$ signalling to attenuate cognitive impairment in mice and senescence of neural stem cells induced by D-galactose. Neurochem Res 43(2):430-440

33. Go G-Y, Jo A, Seo D-W, Kim W-Y, Kim YK, So E-Y et al (2020) Ginsenoside $\mathrm{Rb} 1$ and $\mathrm{Rb} 2$ upregulate Akt/mTOR signaling-mediated muscular hypertrophy and myoblast differentiation. J ginseng Res 44(3):435-441

34. Hsieh Y-H, Deng J-S, Chang Y-S, Huang G-J (2018) Ginsenoside $\mathrm{Rh} 2$ ameliorates lipopolysaccharide-induced acute lung injury by regulating the TLR4/PI3K/Akt/mTOR, Raf-1/MEK/ERK, and Keap1/Nrf2/HO-1 signaling pathways in mice. Nutrients 10(9):1208
35. Yang J, Li S, Wang L, Du F, Zhou X, Song Q et al (2018) Ginsenoside $\mathrm{Rg} 3$ attenuates lipopolysaccharide-induced acute lung injury via MerTK-dependent activation of the PI3K/AKT/mTOR pathway. Front Pharmacol 9:850

36. Huang Y, Wu D, Fan W (2014) Protection of ginsenoside Rg1 on chondrocyte from IL-1 $\beta$-induced mitochondria-activated apoptosis through PI3K/Akt signaling. Mol Cell Biochem 392(1):249-257

37. Chen S, Li X, Wang Y, Mu P, Chen C, Huang P et al (2019) Ginsenoside $\mathrm{Rb} 1$ attenuates intestinal ischemia/reperfusion-induced inflammation and oxidative stress via activation of the PI3K/Akt/ Nrf2 signaling pathway. Mol Med Rep 19(5):3633-3641

38. Kim DH, Park CH, Park D, Choi YJ, Park MH, Chung KW et al (2014) Ginsenoside Rc modulates Akt/FoxO1 pathways and suppresses oxidative stress. Arch Pharm Res 37(6):813-820

39. Liu Y, Yi L, Wang L, Chen L, Chen X, Wang Y (2016) Ginsenoside Rg1 protects human umbilical cord blood-derived stromal cells against tert-butyl hydroperoxide-induced apoptosis through Akt-FoxO3a-Bim signaling pathway. Mol Cell Biochem 421(1):75-87

40. Jeong J-J, Kim B, Kim D-H (2014) Ginsenoside Rb1 eliminates HIV-1 (D3)-transduced cytoprotective human macrophages by inhibiting the AKT pathway. J Med Food 17(8):849-854

41. Xin C, Quan H, Kim J-M, Hur Y-H, Shin J-Y, Bae H-B et al (2019) Ginsenoside Rb1 increases macrophage phagocytosis through p38 mitogen-activated protein kinase/Akt pathway. J Ginseng Res 43(3):394-401

42. Qiu X-M, Bai X, Jiang H-F, He P, Wang J-H (2014) 20-(s)-ginsenoside $\operatorname{Rg} 3$ induces apoptotic cell death in human leukemic U937 and HL-60 cells through PI3K/Akt pathways. Anticancer Drugs 25(9): 1072-1080

43. Zeng D, Wang J, Kong P, Chang C, Li J, Li J (2014) Ginsenoside Rg3 inhibits HIF- $1 \alpha$ and VEGF expression in patient with acute leukemia via inhibiting the activation of PI3K/Akt and ERK1/2 pathways. Int J Clin Exp Pathol 7(5):2172

44. Deng X, Zhao J, Qu L, Duan Z, Fu R, Zhu C et al (2020) Ginsenoside $\mathrm{Rh} 4$ suppresses aerobic glycolysis and the expression of PD-L1 via targeting AKT in esophageal cancer. Biochem Pharmacol 178:114038

45. Lu M, Fei Z, Zhang G (2018) Synergistic anticancer activity of 20 (S)-Ginsenoside $\operatorname{Rg} 3$ and Sorafenib in hepatocellular carcinoma by modulating PTEN/Akt signaling pathway. Biomed Pharmacother 97:1282-1288

46. Yang X, Gao M, Miao M, Jiang C, Zhang D, Yin Z et al (2020) Combining combretastatin A4 phosphate with ginsenoside $\mathrm{Rd}$ synergistically inhibited hepatocellular carcinoma by reducing HIF-1 $\alpha$ via PI3K/AKT/mTOR signalling pathway. J Pharm Pharmacol 63:263

47. Chen F, Zheng S-L, Hu J-N, Sun Y, He Y-M, Peng H et al (2016) Octyl ester of ginsenoside Rh2 induces apoptosis and G1 cell cycle arrest in human HepG2 cells by activating the extrinsic apoptotic pathway and modulating the Akt/p38 MAPK signaling pathway. J Agric Food Chem 64(40):7520-7529

48. Jiang J, Yuan Z, Sun Y, Bu Y, Li W, Fei Z (2017) Ginsenoside $\mathrm{Rg} 3$ enhances the anti-proliferative activity of erlotinib in pancreatic cancer cell lines by downregulation of EGFR/PI3K/Akt signaling pathway. Biomed Pharmacother 96:619-625

49. Hong S, Cai W, Huang Z, Wang Y, Mi X, Huang Y et al (2020) Ginsenoside Rg3 enhances the anticancer effect of 5-FU in colon cancer cells via the PI3K/AKT pathway. Oncol Rep 44(4): 1333-1342

50. Wang J-H, Nao J-F, Zhang M, He P (2014) 20 (s)-ginsenoside $\mathrm{Rg} 3$ promotes apoptosis in human ovarian cancer HO-8910 cells through PI3K/Akt and XIAP pathways. Tumor Biol 35(12):11985-11994 
51. Shi X, Yang J, Wei G (2018) Ginsenoside 20 (S)-Rh2 exerts anti-cancer activity through the Akt/GSK3 $\beta$ signaling pathway in human cervical cancer cells. Mol Med Rep 17(3):4811-4816

52. Zhang E, Shi H, Yang L, Wu X, Wang Z (2017) Ginsenoside $\mathrm{Rd}$ regulates the Akt/mTOR/p70S6K signaling cascade and suppresses angiogenesis and breast tumor growth. Oncol Rep 38(1):359-367

53. Kim B-M, Kim D-H, Park J-H, Surh Y-J, Na H-K (2014) Ginsenoside $\mathrm{Rg} 3$ inhibits constitutive activation of NF- $\mathrm{KB}$ signaling in human breast cancer (MDA-MB-231) cells: ERK and Akt as potential upstream targets. J cancer Prev 19(1):23

54. Hong Y, Fan D (2019) Ginsenoside Rk1 induces cell death through ROS-mediated PTEN/PI3K/Akt/mTOR signaling pathway in MCF-7 cells. J Funct Foods 57:255-265

55. Liu Y, Fan D (2018) Ginsenoside Rg5 induces apoptosis and autophagy via the inhibition of the PI3K/Akt pathway against breast cancer in a mouse model. Food Funct 9(11):5513-5527

56. Li KF, Kang CM, Yin XF, Li HX, Chen ZY, Li Y et al (2018) Ginsenoside Rh2 inhibits human A172 glioma cell proliferation and induces cell cycle arrest status via modulating Akt signaling pathway. Mol Med Rep 17(2):3062-3068

57. Guan N, Huo X, Zhang Z, Zhang S, Luo J, Guo W (2015) Ginsenoside Rh2 inhibits metastasis of glioblastoma multiforme through Akt-regulated MMP13. Tumor Biol 36(9):6789-6795

58. Li C, Gao H, Feng X, Bi C, Zhang J, Yin J (2020) Ginsenoside $\mathrm{Rh} 2$ impedes proliferation and migration and induces apoptosis by regulating NF- $\mathrm{KB}, \mathrm{MAPK}$, and $\mathrm{PI} 3 \mathrm{~K} / \mathrm{Akt} / \mathrm{mTOR}$ signaling pathways in osteosarcoma cells. J Biochem Mol Toxicol 34(12):e22597

59. Xie Q, Wen H, Zhang Q, Zhou W, Lin X, Xie D et al (2017) Inhibiting PI3K-AKt signaling pathway is involved in antitumor effects of ginsenoside Rg3 in lung cancer cell. Biomed Pharmacother 85:16-21

60. Meng L, Ji R, Dong X, Xu X, Xin Y, Jiang X (2019) Antitumor activity of ginsenoside $\mathrm{Rg} 3$ in melanoma through downregulation of the ERK and Akt pathways. Int J Oncol 54(6):2069-2079

61. Cheng C-C, Yang S-M, Huang C-Y, Chen J-C, Chang W-M, Hsu S-L (2005) Molecular mechanisms of ginsenoside Rh2-mediated G 1 growth arrest and apoptosis in human lung adenocarcinoma A549 cells. Cancer Chemother Pharmacol 55(6):531-540

62. Park S, Lee H-J, Jeong S-J, Song HS, Kim M, Lee H-J et al (2011) Inhibition of JAK1/STAT3 signaling mediates compound
K-induced apoptosis in human multiple myeloma U266 cells. Food Chem Toxicol 49(6):1367-1372

63. Nag SA, Qin J, Wang W, Wang M-H, Wang H, Zhang R (2012) Ginsenosides as anticancer agents: in vitro and in vivo activities, structure-activity relationships, and molecular mechanisms of action. Front Pharmacol 3:25

64. Guo J-Q, Zheng Q-H, Chen H, Chen L, Xu J-B, Chen M-Y et al (2014) Ginsenoside Rg3 inhibition of vasculogenic mimicry in pancreatic cancer through downregulation of VE-cadherin/ EphA2/MMP9/MMP2 expression. Int J Oncol 45(3):1065-1072

65. Li Y, Lu J, Bai F, Xiao Y, Guo Y, Dong Z (2018) Ginsenoside Rg3 suppresses proliferation and induces apoptosis in human osteosarcoma. BioMed Res Int 2018:4306579

66. Wang W, Zhao Y, Rayburn ER, Hill DL, Wang H, Zhang R (2007) In vitro anti-cancer activity and structure-activity relationships of natural products isolated from fruits of Panax ginseng. Cancer Chemother Pharmacol 59(5):589-601

67. Wong VKW, Cheung SSF, Li T, Jiang ZH, Wang JR, Dong $\mathrm{H}$ et al (2010) Asian ginseng extract inhibits in vitro and in vivo growth of mouse lewis lung carcinoma via modulation of ERK-p53 and NF- $\kappa B$ signaling. J Cell Biochem 111(4):899-910

68. Mai TT, Moon J, Song Y, Viet PQ, Van Phuc P, Lee JM et al (2012) Ginsenoside F2 induces apoptosis accompanied by protective autophagy in breast cancer stem cells. Cancer Lett 321(2):144-153

69. Wu Q, Deng J, Fan D, Duan Z, Zhu C, Fu R et al (2018) Ginsenoside $\mathrm{Rh} 4$ induces apoptosis and autophagic cell death through activation of the ROS/JNK/p53 pathway in colorectal cancer cells. Biochem Pharmacol 148:64-74

70. Yun U-J, Lee IH, Lee J-S, Shim J, Kim Y-N (2020) Ginsenoside Rp1, a ginsenoside derivative, augments anti-cancer effects of actinomycin D via downregulation of an AKT-SIRT1 pathway. Cancers 12(3):605

Publisher's Note Springer Nature remains neutral with regard to jurisdictional claims in published maps and institutional affiliations. 